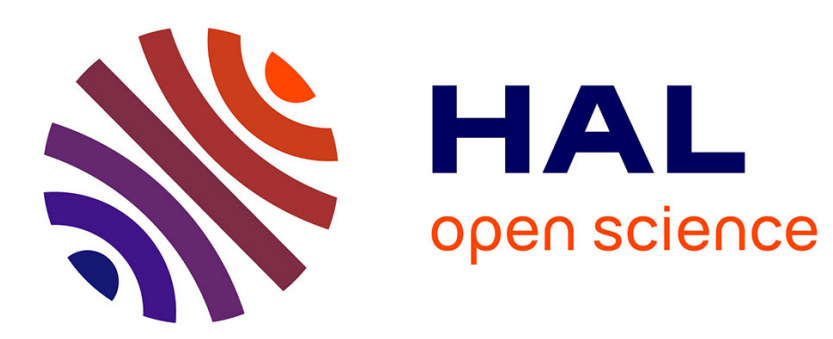

\title{
Genetic variations involved in interindividual variability in carotenoid status.
}

Patrick Borel

\section{To cite this version:}

Patrick Borel. Genetic variations involved in interindividual variability in carotenoid status.. Molecular Nutrition and Food Research, 2012, 56 (2), pp.228-40. 10.1002/mnfr.201100322 . inserm00628593

\section{HAL Id: inserm-00628593 https://www.hal.inserm.fr/inserm-00628593}

Submitted on 3 Oct 2011

HAL is a multi-disciplinary open access archive for the deposit and dissemination of scientific research documents, whether they are published or not. The documents may come from teaching and research institutions in France or abroad, or from public or private research centers.
L'archive ouverte pluridisciplinaire HAL, est destinée au dépôt et à la diffusion de documents scientifiques de niveau recherche, publiés ou non, émanant des établissements d'enseignement et de recherche français ou étrangers, des laboratoires publics ou privés. 


\section{Genetic variations involved in interindividual variability in}

\section{carotenoid status}

Patrick BOREL ${ }^{1,2,3}$

${ }^{1}$ INRA, UMR1260 "Lipid Nutrients and Prevention of Metabolic Diseases", F-13385, Marseille, France.

${ }^{2}$ INSERM, U1025 "Bioavailability of Micronutrients", F-13385, Marseille, France.

${ }^{3}$ Univ Aix-Marseille, F-13385, Marseille, France.

Address: UMR 1260 INRA, 27 Bd Jean Moulin, 13385 Marseille cedex 5 France, Tel: +334 912941 11, Fax: +33491782101.

E-mail: $\underline{\text { Patrick.Borel@univmed.fr }}$

\section{Abbreviations :}

ABCG5: ATP-binding cassette sub-family G member 5

BCMO1: $\beta, \beta$-carotene-15,15'-monooxygenase

BCDO2: $\beta, \beta$-carotene-9,9'-oxygenase

CD36: Cluster determinant 36

FABP : Fatty acid binding protein

HR-LBP: Human retinal lutein-binding protein

GSTP1: Glutathione S-transferase Pi 1

GWAS: Genome-wide association study

NPC1L1: Niemann Pick C1-like 1

SNP: Single nucleotide polymorphism 
SR-BI: Scavenger receptor class B type I

Key words: bioavailability, genetic polymorphisms, nutrigenetic, personalized nutrition, SNP. 


\section{Abstract}

A common observation in clinical studies dedicated to carotenoids is the huge interindividual variability in absorption and blood and tissue responses in these compounds. The recent discovery that several proteins are involved in carotenoid metabolism in humans has prompted a possible explanation for this phenomenon: genetic variants in genes encoding for these proteins may affect their expression or activity, and in turn carotenoid metabolism and carotenoid status. The proteins clearly identified so far are: the carotene oxygenases BCMO1 ( $\beta, \beta$-carotene-15,15'-monooxygenase) and $\mathrm{BCDO} 2$ ( $\beta, \beta$-carotene-9,9'-oxygenase), which are involved in carotenoid cleavage, SR-BI (scavenger receptor class B type I), CD36 (Cluster Determinant 36)) and NPC1L1 (Niemann Pick C1-like 1), which are involved in carotenoid uptake by cells, and GSTP1 (glutathione S-transferase Pi 1) and HR-LBP (human retinal lutein-binding protein), which are involved in the transport of xanthophylls in the retina. Other proteins, such as ABCG5 (ATP-binding cassette sub-family G member 5) and the FABPs (fatty acid binding proteins) are also apparently involved, although firmer evidence is still required. A genome-wide association study, as well as several candidate gene association studies, have shown that groups of subjects bearing different alleles in single nucleotide polymorphisms located in or near several of the above-mentioned genes display different blood and/or tissue concentrations of carotenoids. Further studies are needed to identify all the proteins involved in carotenoid metabolism and assess whether other types of genetic variation, e.g. copy number variants and epigenetic modifications, can modulate carotenoid status. One potential application of such research could be personalized dietary guidelines for carotenoids according to individual genetic characteristics. 


\section{Introduction}

Carotenoids are lipid microconstituents found mainly in foods of plant origin. They can be divided into provitamin A and non-provitamin A carotenoids. The main provitamin A carotenoids are $\beta$-carotene, $\alpha$-carotene and $\beta$-cryptoxanthin. These carotenoids can be considered as vitamin A, i.e. retinyl esters, when dietary preformed vitamin A fails to meet the body's needs. The non-provitamin A carotenoids, the main ones being lutein, lycopene and zeaxanthin, are not considered as vitamins because their essentiality for humans is not yet proven. However, numerous studies have suggested that they can be beneficial for human health $[1,2]$, and some of them may play a specific biological role in humans, e.g. in lutein and eye biology [3-6].

Interest in the metabolism of carotenoids has increased in the last decade because of the associations between several degenerative diseases, e.g. cancers, cardio-vascular diseases, and eye diseases, and either the dietary intake of these molecules or their blood or tissue concentrations. In addition, clinical studies performed with carotenoids have systematically observed a huge variability in blood and, when measured, tissue response, i.e. variation in concentrations of dietary carotenoids. This has even led some researchers to divide subjects into low and high responders to carotenoids. It was further observed that the low or high responder phenotype was an intrinsic individual characteristic [7] and it was hypothesized that this was due to genetic characteristics of the individuals [7]. However, when this hypothesis was advanced, only BCMO1 ( $\beta, \beta$-carotene-15,15'-monooxygenase) was known to participate in carotenoid metabolism and it was not possible to explain the interindividual variability by genetic variations for this enzyme only. In the following decade several proteins were found to be involved in the intestinal uptake, intracellular transport and cleavage of carotenoids. A reasonable hypothesis can thus be proposed: genetic variants in genes that encode these 
proteins may affect expression or activity of these proteins and in turn carotenoid metabolism and carotenoid status.

This review first presents proteins involved in carotenoid metabolism in humans. It then focuses on SNPs (single nucleotide polymorphisms) that have been associated with carotenoid status and examines other types of genetic variations that might affect carotenoid status. Lastly we discuss the potential implications of these genetic variations in dietary guidelines for carotenoids. 


\section{HUGE INTERINDIVIDUAL VARIABILITY IN BLOOD AND TISSUE RESPONSES TO DIETARY}

\section{CAROTENOIDS}

A huge interindividual variability in blood and tissue concentrations of carotenoids is consistently observed in healthy subjects. Obviously, this variability is in part due to the variability in intake of these dietary microconstituents. However, most clinical studies dedicated to measuring blood and tissue responses to diets supplemented with carotenoids, or to meals enriched with carotenoids, have observed a huge interindividual variability in absorption efficiency of carotenoids and in blood and tissue responses to dietary carotenoids [7-12]. An example of this variability is shown in Figure 1. This has even led some researchers to assert that some subjects are "non-responders" to carotenoids [11, 13-15]. Although the term "non-responder" is inappropriate because all healthy subjects are apparently responders to dietary carotenoids, since no healthy subject without detectable carotenoids in their blood or tissue has ever been found, there is clearly a huge variability in blood and tissue response to dietary carotenoids in the healthy population. As hypothesized in Section 3 this effect is probably due to variations in genes that encode proteins involved in carotenoid absorption and metabolism.

\section{PROTEINS DIRECTLY OR INDIRECTLY INVOLVED IN CAROTENOID METABOLISM}

Until recently it was assumed that carotenoids, being fat-soluble, simply followed lipids from the lipid droplets present in the gastro-intestinal lumen during digestion [16-18] to the intracellular lipid droplets where they are stored [19-21]. More precisely, it was assumed that they were first transferred from the food matrix, where they were embedded in the fat phase of the meal, and then transferred to mixed micelles during triglyceride lipolysis by pancreatic 
lipase, before being absorbed by passive diffusion, incorporated in chylomicrons and distributed to tissues together with triglycerides and cholesterol. However, the reality is more complex because several proteins are involved, or are suspected of being involved, at different stages in this pathway. First, it is assumed that a digestive enzyme is involved in the hydrolysis of the carotenoids that are esterified. Second, it has been suggested that as observed for cholesterol, apical membrane proteins of the enterocyte are involved in the uptake of carotenoids. Finally, proteins are thought to be involved in the intracellular transport of carotenoids across the water environment of the cells, etc. Below we present a state-of-theart review concerning the proteins known so far to be involved in carotenoid metabolism in humans.

\subsection{CANDIDATE PROTEINS FOR HYDROLYSIS OF CAROTENOID ESTERS IN THE INTESTINAL LUMEN}

Although most dietary carotenoids are non-esterified, some carotenoids, e.g. xanthophylls present in supplements, can be esterified. Like other lipids it is assumed that only the free forms of carotenoids can be absorbed by the enterocyte. Thus it is assumed that an enzyme in the gastro-intestinal lumen and/or in the brush border of the enterocyte is responsible for the hydrolysis of carotenoid esters. Several candidates can be proposed. The first candidate, in order of appearance in the gastro-intestinal tract, is gastric lipase, which can hydrolyse up to $17.5 \%$ of the triacyglycerols [22]. However, no data are available on the ability of this lipase to hydrolyse carotenoid esters. A second candidate could be pancreatic lipases, pancreatic lipase and pancreatic lipase-related protein 2 , which are able to hydrolyse retinyl-palmitate [23]. Unfortunately, here again there are no available data on the ability of these lipases to hydrolyse carotenoid esters. The third and principal candidate is obviously cholesterol ester hydrolase [24-27], because it has a broad substrate specificity and because it is known to be involved in the hydrolysis of zeaxanthin esters in vitro [28]. However, we note that in vivo 
studies using knock-out mice [29, 30] to confirm the involvement of this enzyme on tocopherol ester hydrolysis in vitro [24-27], have failed to confirm its involvement in its hydrolysis in vivo. A last candidate could be a brush border esterase, but again no data are available on this possibility. To conclude, several digestive enzymes could be involved in carotenoid ester hydrolysis in the human upper gastro-intestinal tract, but no such enzyme has yet been firmly identified.

\subsection{PROTEINS INVOLVED IN UPTAKE AND SECRETION OF CAROTENOIDS BY CELLS}

The first cell that makes contact with dietary carotenoids is obviously the enterocyte. Most of the studies dedicated to understanding mechanisms by which carotenoids are taken up and secreted by cells have been performed with intestinal cells or tissues. The first study was performed by the group of Hollander in the 1970s. This group, using rat everted intestinal sacs, concluded that absorption of $\beta$-carotene, and by extension absorption of all the carotenoids, was passive [31]. Although well conducted, this study was obviously limited by the technology available at that time. New studies performed during the last decade by several independent research teams have shown that the mechanism of absorption is actually more complex than was previously assumed: passive diffusion probably occurs at high, pharmacological concentrations of carotenoids, while a protein-mediated transport takes place at dietary doses.

Available data suggest that there is no specific protein involved in uptake/efflux of carotenoid by cells. Recent studies suggest that it is lipid transporters - and especially cholesterol transporters - that are mainly involved in carotenoid uptake/efflux by cells. 


\subsubsection{The scavenger receptor class B type I (SR-BI)}

The first lipid transporter involved in carotenoid uptake is SR-BI. This lipid transporter is a single-chain trans-membrane glycoprotein of $80 \mathrm{kDa}$. SR-BI is found in various cell types including liver, testis, ovaries and macrophages [32], as well as on the brush border membrane of the enterocyte from the duodenum to the colon [33]. Its main ligands are HDL (high density lipoproteins), but also LDL (low density lipoproteins) and VLDL (very low density lipoproteins), anionic phospholipids and apoptotic cells [32]. SR-BI is able to facilitate the selective entry into the cell compartment of esterified cholesterol recovered in HDL [34]. At the intestinal level, it was first shown that SR-BI facilitated the uptake of free cholesterol, but also of esterified cholesterol, phospholipids and triacylglycerol hydrolysis products, thus displaying a broad ligand specificity [35, 36]. In 2005 SR-BI was identified for the first time as playing a role in the uptake of the carotenoid lutein at the intestinal level using Caco-2 cells [37], and this result was rapidly extended to other carotenoids, such as $\beta$ carotene [38], zeaxanthin [39] and lycopene [40], and to other cell types. SR-BI has also been shown to be involved in carotenoid uptake by retina pigment eptithelium [39], and it has been suggested that it is involved in the preferential uptake of xanthophylls by the macula [39]. The fact that SR-BI is important for carotenoid metabolism is supported by a recent study showing that its expression is modulated by provitamin A carotenoids. More precisely, by using both mouse models and human cell lines, it has been shown that carotenoid absorption by SR-BI is subject to control by retinoid signalling. Retinoic acid induces the expression of the intestinal transcription factor ISX, which represses the expression of both SR-BI and BCMO1. BCMO1 acts downstream of SR-BI and converts absorbed beta-carotene into the retinoic acid precursor, retinaldehyde [41]. Thus there is a diet-responsive regulatory network that controls SR-BI mediated carotenoid absorption by a negative feedback regulation. 
The role of SR-BI is not limited to the uptake of lipid molecules. It has been observed to function in both directions in the intestine [42] and in other tissues [34]. Concerning lipid micronutrients, it has been shown that SR-BI is able to efflux both vitamin E [43] and vitamin D [44] from Caco-2 cells. It may therefore be involved in the efflux of carotenoids from the enterocyte to the intestinal lumen, which may explain in part the very low absorption efficiency of these compounds, as also in the efflux of carotenoids from other tissues. Unfortunately, no data are available on the possible involvement of SR-BI in carotenoid efflux in any cell type.

\subsubsection{Cluster Determinant 36 (CD36)}

Another scavenger receptor apparently involved in carotenoid uptake by cells is FAT (fatty acid translocase), also known as CD36 in humans. This trans-membrane glycoprotein of $90 \mathrm{kDa}$ is mainly expressed in epithelial cells, adipocytes, platelets and macrophages [32], but it is also expressed in the duodenum and the jejunum [33]. As SR-BI, it can interact with a broad variety of ligands [32]. CD36 was first shown to be involved in $\beta$-carotene uptake by cells using transfected COS-7 cells and mouse brush border membrane vesicles [38]. This involvement in carotenoid uptake by cells was confirmed recently in mouse 3T3-L1 adipocytes and in mouse adipose tissue cultures [45].

\subsubsection{Niemann Pick C1-like 1 (NPC1L1)}

NPC1L1 is a $135 \mathrm{kDa}$ protein widely expressed in human tissues, especially in the liver and the plasma membrane of the intestinal cell [46-50]. It is the main cholesterol and phytosterol transporter in the intestine [51]. NPC1L1 has been shown to be involved in both $\alpha$-tocopherol [52] and $\gamma$-tocotrienol [53] intestinal absorption using Caco-2 cells and in situ perfusions in rats. Results are less clearcut regarding carotenoids: in a first study [54], ezetimibe, a drug used to diminish dietary cholesterol absorption and that inhibits NPC1L1, 
significantly inhibited the uptake of several carotenoids in Caco-2 cells. Conversely, in a second study that focused on lycopene [40], neither ezetimibe nor blocking antibody directed against NPC1L1 impaired its absorption in Caco-2. Further experiments are thus required to thoroughly assess the role of NPC1L1 in carotenoid metabolism.

\subsubsection{The ABC transporters}

The ABC transporters are a superfamily of transmembrane proteins able to transport a wide variety of substrates including drugs, lipids, bile salts, amino acids, peptides, proteins and oses. Most of these transporters are efflux proteins [55] that need ATP hydrolysis by two sites of ligation to ATP $[56,57]$. In particular, the ABCG5/G8 heterodimer is critical in sterol homeostasis. The complex ABCG5/G8 acts as an efflux pump in the enterocyte, where it limits mainly phytosterol absorption. Interestingly, one study suggested a role of ABCG5 (ATP-binding cassette sub-family G member 5) in lutein metabolism [58]. However, it was an association study that showed only an association (near-significant) between a genetic variant in ABCG5 and plasma lutein concentration. Dedicated studies are therefore required to assess the possible involvement of $\mathrm{ABC}$ transporters in carotenoid metabolism.

In conclusion, it appears that several lipid transporters are involved in uptake/efflux of carotenoids by the intestinal cell (Figure 2) as well as by other cells (Table 1). However, the relative contribution of these transporters to the net uptake/efflux of each carotenoid species in different tissues is not known. In addition, it is likely that not all the transporters involved, peculiarly the $\mathrm{ABC}$ transporters, have yet been identified. 


\subsection{PROTEINS INVOLVED IN INTRACELLULAR TRANSPORT OF CAROTENOIDS}

The intracellular transport of carotenoids is not well known. It is assumed that being insoluble in water, these compounds require either intracellular proteins to cross the water compartments of the cells, or incorporation into intracellular membranes, to be transported within the cells.

\subsubsection{Carotenoid-binding proteins}

Two xanthophyll-binding proteins have been described in human retina: GSTP1 (glutathione S-transferase Pi 1) [59], which binds zeaxanthin and (3R,3'S-meso)-zeaxanthin, and HR-LBP (human retinal lutein-binding protein), which binds lutein [60]. Apparently noone has tested whether these proteins are able to bind other carotenoids, e.g. $\beta$-carotene and lycopene, but these proteins, or proteins of the same family, are good candidates for intracellular transport of carotenoids in other tissues.

\subsubsection{Fatty acid-binding proteins (FABPs)}

The hypothesis that FABPs can participate in the intracellular transport of carotenoids comes from Hollander's group. This team suggested, from results showing interactions between a fat soluble vitamin (phylloquinone) and linoleic acid, that a FABP might also be a carrier for fat-soluble micronutrients [61]. The fact that FABPs are able to bind different hydrophobic molecules [62, 63] supports this hypothesis. Two main fatty acid-binding proteins are found in human tissues: intestinal FABP, mainly recovered in the intestine, and liver FABP, recovered in the liver but also in other tissues. It is hypothesized that FABPs allow a specific intracellular trafficking of their ligands to their respective metabolic fates. Although dedicated studies need to be performed to verify whether intestinal and/or liver FABP are involved in intracellular transport of carotenoids, the fact that in a genetic association study, a genetic variant in intestinal FABP was associated with fasting plasma 
lycopene concentrations [64] can be considered as a first argument that FABPs may be involved in the intracellular transport of some carotenoids.

\subsection{PROTEINS INVOLVED IN CAROTENOID CLEAVAGE}

The requirements for vitamin A can be satisfied either by animal foods containing preformed vitamin A, i.e. retinyl esters, or by plant foods containing provitamin A carotenoids. In humans, two different carotene oxygenases are involved in carotenoid cleavage: BCMO1 and BCDO2 ( $\beta, \beta$-carotene-9,9'-oxygenase) [65]. BCMO1 is responsible for the symmetric cleavage $[66,67]$, while $\mathrm{BCDO} 2$ is responsible for the asymmetric cleavage. Immunohistochemical analysis revealed that BCMO1 was expressed in epithelial cells and in a variety of human tissues [68]. It is now assumed that it is the main enzyme responsible for vitamin A synthesis both in the intestine and the liver, and also for vitamin A synthesis in different tissues when local concentrations in vitamin A are insufficient. The biological role of $\mathrm{BCDO} 2$ has been unravelled recently [69]: it was shown in $\mathrm{BCDO} 2-$ deficient mice and in human cell cultures that $\mathrm{BCDO} 2$ was located in the mitochondria and that its main role was apparently to degrade carotenoids to protect mitochondria from carotenoid-induced dysfunctions. Interestingly, carotenoid homeostasis was impaired in BCDO2-deficient mice, leading to accumulation of carotenoids in several tissues.

\subsection{PROTEINS INVOLVED IN LIPOPROTEIN METABOLISM}

Because carotenoids are transported by blood lipoproteins [70], it has been hypothesized that genes involved in lipoprotein metabolism, e.g. genes that encode for apolipoproteins or for endothelial lipases, may indirectly affect blood concentrations of carotenoids by modulating the number, and/or the lipid composition, of the vehicles that transport carotenoids in the blood. This hypothesis is supported by several association studies showing 
that blood carotenoid concentrations were significantly different in groups of subjects who bore different genetic variants in apolipoprotein A-IV [71], apolipoprotein B [71], apolipoprotein E [72], hepatic lipase [64] and lipoprotein lipase [73].

In conclusion, it appears that several proteins are involved at numerous steps in carotenoid metabolism (Table 1). Some are specific, e.g. BCMO1, others are non-specific, e.g. cholesterol transporters, and still others are indirectly involved, e.g. apolipoproteins. The metabolism of carotenoids within the human body is therefore more complex than previously thought, i.e. a simple distribution of carotenoids within the lipid compartments of the body depending on the solubility of carotenoids in the different lipid phases. Several proteins are clearly involved in blood and tissue concentrations of carotenoids.

\section{HYPOTHESIS CONCERNING THE MODULATION OF CAROTENOID STATUS VIA GENETIC MODULATION OF EXPRESSION OR ACTIVITY OF PROTEINS INVOLVED IN CAROTENOID METABOLISM}

The fact that proteins are involved in cellular uptake, intracellular transport and cleavage of carotenoids raises the question of the consequences of modulations in the expression or activity of these proteins on blood and tissue concentrations of these compounds. The expression and activity of proteins can be modulated by several factors, including genetic ones. Genetic variations in or near genes that encode proteins may affect protein expression, e.g. a genetic variation that affects the binding of a transcription factor in the promoter region of a gene, or protein activity, e.g. a genetic variation that leads to a functional modification in the amino acid sequence of the protein, and in turn the ability of these proteins to accurately perform their function in the metabolism. Concerning carotenoids, it can be hypothesized that 
genetic variations in genes that encode proteins involved in uptake, transport, and cleavage of these compounds will affect their absorption efficiency (Figure 3) as well as their blood and tissue concentrations. This hypothesis is supported by several studies showing associations between genetic variants in genes involved, or suspected to be involved, in carotenoid metabolism and blood and tissue concentrations of carotenoids.

\section{MUTATIONS AFFECTING CAROTENOID STATUS}

Very high skin concentrations of carotenoids cause carotenodermia. Carotenodermia is usually due to very high intake of carotenoids, such as in people, e.g. infants, eating large amounts of carrots or carrot-derived products. Yet cases of carotenodermia and/or hypercarotenemia have also been reported in which subjects had normal carotenoid intakes. It was hypothesized that these subjects had an impairment in the conversion of carotenoids to retinal by BCMO1 [74-77]. In support of this hypothesis a mutation that explains a case of metabolic carotenodermia has been identified recently [78]. The mutation led to the replacement of a threonine with a methionine, resulting in a $90 \%$ reduction of $\mathrm{BCMO} 1$ activity. The hypercarotenemia was explained by the fact that BCMO1, which is saturated during normal dietary conditions, cleaved less dietary carotenoids than usual, leading to higher blood concentrations of carotenoids.

\section{MAIN SINGLE NUCLEOTIDE POLYMORPHISMS (SNPS) AFFECTING CAROTENOID STATUS}

GWAS (genome-wide association study) is today the most popular approach for identifying genetic variants and thus genes associated with phenotypes. In this approach, the frequency of genetic variants (often involving hundreds of thousands of SNPs studied simultaneously) is 
investigated in large numbers of subjects (again often using DNA from thousands of subjects). There is only one GWAS study dedicated to identifing the main genetic variants associated with blood concentration of carotenoids [79]. This study, which was performed in a cohort of Italian and replicated with two US cohorts, showed that an SNP near the BCMO1 gene, rs6564851, was significantly associated with plasma concentration of several carotenoids [12]. More precisely, the G allele at this SNP was simultaneously associated with higher concentrations of $\alpha$ and $\beta$-carotene and with lower concentrations of lycopene, lutein and zeaxanthin. This result confirms the key role of this enzyme in the metabolism of provitamin A carotenoids and shows that it is also involved, by an unknown mechanism, in the blood status of non-provitamin A carotenoids. We note that the association between lutein and BCMO1 genetic variants was also found in another study [80]. Although closely associated it was calculated that rs6564851 explained $1.9 \%$ of the variance in plasma $\beta$ carotene concentration [79]. Thus other genetic variations, which could be the SNPs identified in candidate gene association studies (see Section 6), are probably involved. It is likely that the genetic variance involves several genetic variants with very small effects that cannot be detected in GWAS studies. The problem with GWAS is that to avoid false positive associations, it requires a dramatically low $p$-value threshold $\left(p<5 \times 10^{-7}\right)$ and so weaker associations have not yet been reported.

\section{OTHER SNPS AFFECTING CAROTENOID STATUS IDENTIFIED BY CANDIDATE GENE} ASSOCIATION STUDIES

Several candidate gene association studies have been performed in the past five years to assess whether SNPs in genes suspected to modulate carotenoid metabolism directly or indirectly can affect blood or tissue concentrations of carotenoids. The results of these studies 
are summarized in Table 2. In summary, these studies have confirmed the key role of genetic variants in BCMO1 on carotenoid status that was observed in the GWAS study on carotenoid status [79] (see previous section). They have also found that, as expected, genetic variants in proteins shown to be involved in carotenoid metabolism in cell studies, e.g. SR-BI and CD36, apparently affect carotenoid status. Finally, they have potentially identified other genes/proteins involved in carotenoid status, e.g. apolipoproteins, ABCG5, liver FABP, although the role of these genes/proteins and the effect of their genetic variants on carotenoid metabolism need to be confirmed in dedicated molecular/functional studies.

\section{OTHER TYPES OF GENETIC VARIATION THAT MIGHT AFFECT CAROTENOID STATUS}

It is likely that the genetic component of interindividual variability in carotenoid status is due to the sum of effects due to variants in numerous genes. Other genetic and epigenetic variations may also contribute to interindividual variability in carotenoid status. Another genetic variation that occurs widely in the human genome is copy number variants. To date, there are no published studies of copy number variants and carotenoid status, but it is reasonable to expect such variants to be responsible for inter-individual variation in the activities of proteins involved in carotenoid metabolism. It is now assumed that epigenetic modifications of DNA, i.e. DNA methylation patterns (CpG sites), acetylation ubiquitination of histones, and very small (non-coding) RNAs (miRNA), play a major role in controlling gene expression. Given that miRNA regulate expression of about one third of all proteinencoding genes across all cellular processes investigated [81], there is a high likelihood that they can play a role in carotenoid metabolism and thus in carotenoid status. In common with other regions of the genome, the domains encoding miRNA also contain SNPs [82], which adds a further layer of genetic complexity. 


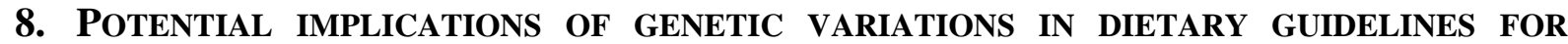 CAROTENOIDS}

The fact that genetic variations can affect absorption efficiency of carotenoids and the conversion of provitamin A carotenoids in vitamin A raises two opposing questions: "Do subjects with low responder genotypes need a higher dietary intake of carotenoids to enjoy the beneficial effects of some carotenoids on health?", and conversely, "Do subjects with high responder genotypes need to avoid high intake of some carotenoids because of the potential toxic effects of some carotenoids [83]?". These questions may also be very relevant with regard to the fight against vitamin A deficiency in developing countries. If genetic variants do affect either absorption efficiency of provitamin A carotenoids, or their conversion into vitamin A, then it may be important to know whether a large proportion of persons in populations at risk of vitamin A deficiency, e.g. populations in some developing countries, bear genetic variants that lead to lower provitamin A activity of carotenoids. In that case it would be better to supplement these populations with preformed vitamin A rather than with provitamin A carotenoids.

\section{CONCLUSIONS}

Available data support the hypothesis that genetic variation is a key factor explaining the huge interindividual variability in carotenoid status. However, much work is still needed to identify all the proteins and genetic variants involved. In addition, such research will probably need to encompass both copy number variants and epigenetic variants. Because a key step of carotenoid status is their absorption efficiency, and because this first step is especially 
variable, it is suggested that dedicated studies should be performed to identify genetic variations explaining this variability. The effect of genetic variants on plasma and tissue concentrations of carotenoids may affect the ability of carotenoids to prevent some diseases (e.g. cardiovascular diseases and cancers). Finally, because several carotenoids are apparently beneficial for health at low, dietary doses and can be hazardous at higher, pharmacological doses, we can envisage adapting recommended dietary intake of carotenoids, or doses of carotenoids incorporated in functional foods/supplements, to population groups carrying genetic variants known to affect carotenoid status. 
Tables

Table 1. Proteins involved in carotenoid metabolism ${ }^{a}$

\begin{tabular}{|c|c|c|c|}
\hline & Intestine & Liver & Other tissues \\
\hline$\beta$-carotene & $\begin{array}{l}\text { SR-BI [38] } \\
\text { CD36 [38] } \\
\text { NPC1L1 [54] } \\
\text { BCMO1 } \\
\text { BCDO2 }\end{array}$ & 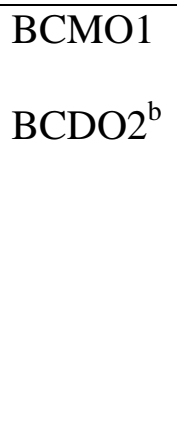 & $\begin{array}{l}\text { SR-BI (retinal pigment } \\
\text { epithelial cells) [39]. } \\
\text { BCDO2 }\end{array}$ \\
\hline Lutein & $\begin{array}{l}\text { SR-BI [37] } \\
\text { NPC1L1 [54] } \\
\text { BCDO2 }\end{array}$ & $\mathrm{BCDO} 2$ & $\begin{array}{l}\text { CD36 (adipose tissue) } \\
{[45]} \\
\text { BCDO2 }\end{array}$ \\
\hline Lycopene & $\begin{array}{l}\text { SR-BI [40] } \\
\text { NPC1L1 }^{\mathrm{c}}[54] \\
\text { BCDO2 }\end{array}$ & BCDO2 & $\begin{array}{l}\text { CD36 (adipose tissue) } \\
{[45]} \\
\text { BCDO2 }\end{array}$ \\
\hline $\begin{array}{l}\text { Other } \\
\text { carotenoids }\end{array}$ & $\begin{array}{l}\text { Carboxyl ester lipase \& } \\
\text { zeaxanthin esters [28] } \\
\text { NPC1L1 }^{\mathrm{d}}[54] \\
\text { BCDO2 }\end{array}$ & $\mathrm{BCDO} 2$ & $\begin{array}{l}\text { SR-BI \& zeaxanthin } \\
\text { (retinal pigment } \\
\text { epithelial cells) [39]. } \\
\text { GSTP1 \& zeaxanthin } \\
\text { (macula) [59] } \\
\text { HR-LBP \& lutein (retina) } \\
\text { [60] }\end{array}$ \\
\hline
\end{tabular}




\begin{tabular}{|l|l|l|l|}
\hline & & & BCDO2 \\
\hline
\end{tabular}

${ }^{a}$ proteins shown to be involved in carotenoid metabolism in cell studies. This table does not show proteins that have been associated only with blood or tissue concentrations of carotenoids.

${ }^{\mathrm{b}} \mathrm{BCDO} 2$ has been recently described as a mitochondial enzyme with a broad substrate specificity [69]. It therefore appears throughout the table, although direct evidence of its involvement for carotenoid cleavage in each tissue is not available.

${ }^{\mathrm{c}}$ not confirmed in another study [40].

${ }^{\mathrm{d}}$ involvement found for $\alpha$-carotene, $\beta$-cryptoxanthin and zeaxanthin. 
Table 2. Genetic variants (SNPs) that have been associated with carotenoid status in candidate gene association studies $^{a}$

\begin{tabular}{|c|c|c|c|c|}
\hline Genes & $\begin{array}{l}\text { Genetic variants } \\
\text { associated }^{\mathrm{b}}\end{array}$ & $\begin{array}{l}\text { Genotypes or } \\
\text { alleles associated } \\
\text { with lower } \\
\text { concentrations of }^{\text {carotenoids }^{c}}\end{array}$ & $\begin{array}{l}\text { Carotenoids } \\
\text { associated }\end{array}$ & References \\
\hline ABCG5 & Q640E & G allele $^{\mathrm{d}}$ & lutein & {$[58]$} \\
\hline apo B & $\begin{array}{l}\text { apo B-516 } \\
\text { apo B-516 }\end{array}$ & $\begin{array}{l}\mathrm{C} \text { allele } \\
\mathrm{C} \text { allele }\end{array}$ & $\begin{array}{l}\text { lycopene } \\
\beta \text {-carotene }\end{array}$ & [71] \\
\hline apo A-IV & apo A-IV-Ser347 & TT & lycopene & [71] \\
\hline apoE & apo E2, E3, E4 & $\begin{array}{l}\mathrm{E} 3 / 2(\text { vs E3/3) } \\
\mathrm{E} 3 / 2(\text { vs E3/3) }\end{array}$ & $\begin{array}{l}\text { lycopene } \\
\alpha \text {-carotene }\end{array}$ & [72] \\
\hline $\mathrm{BCDO} 2$ & $\begin{array}{l}\text { W80X } \\
\text { c. } 196 \mathrm{C}>\mathrm{T}\end{array}$ & $\begin{array}{l}\mathrm{G} \text { allele } \\
\mathrm{T} \text { allele }\end{array}$ & $\begin{array}{l}\beta \text {-carotene } \\
\text { likely } \beta \text {-carotene }^{\mathrm{f}}\end{array}$ & $\begin{array}{l}{[84]} \\
{[85]}\end{array}$ \\
\hline BCMO1 & $\begin{array}{l}\text { rs6564851 } 1^{\mathrm{g}} \\
\text { R267S+A379V } \\
\text { rs7501331 } \\
\text { rs7501331 }\end{array}$ & $\begin{array}{l}379 \mathrm{~A} \\
\mathrm{TT} \\
\mathrm{CT}\end{array}$ & $\begin{array}{l}\text { lycopene, lutein } \\
\text { and zeaxanthin } \\
\beta \text {-carotene } \\
\text { lutein } \\
\text { lutein }\end{array}$ & $\begin{array}{l}799] \\
{[86]} \\
{[80]}\end{array}$ \\
\hline
\end{tabular}




\begin{tabular}{|c|c|c|c|c|}
\hline CD36 & $\begin{array}{l}\text { rs1761667 } \\
\text { rs13230419 }\end{array}$ & $\begin{array}{l}\text { A allele } \\
\text { CC }\end{array}$ & $\begin{array}{l}\text { lutein } 9 \\
\text { lutein }\end{array}$ & [80] \\
\hline HL & HL C-480T & $\begin{array}{l}\mathrm{TT}^{\mathrm{j}} \\
\text { C allele }\end{array}$ & $\begin{array}{l}\alpha \text {-carotene } \\
\beta \text {-carotene }\end{array}$ & [64] \\
\hline $\begin{array}{l}\text { FABP2 (intestinal } \\
\text { FABP) }\end{array}$ & IFABP-Thr & $\mathrm{GG}^{\mathrm{J}}$ & lycopene & [64] \\
\hline LPL & S447X & $\begin{array}{l}\text { X447/X447 vs } \\
\text { S447/S447 }\end{array}$ & $\begin{array}{l}\beta \text {-carotene, } \alpha- \\
\text { carotene and } \beta \text { - } \\
\text { cryptoxanthin }\end{array}$ & [73] \\
\hline SCARB1 & $\begin{array}{l}\text { SR-BI intron } 5 \\
\text { SR-BI intron } 5 \\
\text { SR-BI exon } 1\end{array}$ & $\begin{array}{l}\text { C allele } \\
\text { C allele } \\
\text { GG }\end{array}$ & $\begin{array}{l}\alpha \text {-carotene } \\
\beta \text {-carotene } \\
\beta \text {-cryptoxanthin }\end{array}$ & [71] \\
\hline
\end{tabular}

${ }^{a}$ all data were obtained in humans except those of $\mathrm{BCDO} 2$ that were obtained in cattle and in sheep.

${ }^{\mathrm{b}}$ annotations as found in the publications.

c associated with lower blood (plasma or serum) concentration of carotenoids when not specified.

${ }^{\mathrm{d}}$ near-significant $(p=0.08)$.

e significant only in men.

${ }^{\mathrm{f}}$ associated with yellow fat phenotype, assumed to be related to $\beta$-carotene concentration.

${ }^{\mathrm{g}}$ near the BCMO1gene (identified in a GWAS study).

${ }^{\mathrm{h}}$ allele simultaneously associated with higher $\beta$-carotene and $\alpha$-carotene concentrations.

i associated with macular pigment optical density (assumed to reflect concentration of lutein/zeaxanthin in the macula). 
${ }^{\mathrm{j}}$ significant only in women. 


\section{References}

[1] Rao, A. V., Rao, L. G., Carotenoids and human health. Pharmacol. Res. 2007, 55, $207-$ 216.

[2] Olson, J. A., Carotenoids and human health. Arch. Latinoam. Nutr. 1999, 49, 7S-11S.

[3] Stahl, W., Macular carotenoids: lutein and zeaxanthin. Dev. Ophthalmol. 2005, 38, 70-88.

[4] Krinsky, N. I., Landrum, J. T., Bone, R. A., Biologic mechanisms of the protective role of lutein and zeaxanthin in the eye. Annu. Rev. Nutr. 2003, 23, 171-201.

[5] Yagi, A., Fujimoto, K., Michihiro, K., Goh, B., et al., The effect of lutein supplementation on visual fatigue: A psychophysiological analysis. Appl. Ergon. 2009, 40, 1047-1054.

[6] Ma, L., Lin, X. M., Zou, Z. Y., Xu, X. R., et al., A 12-week lutein supplementation improves visual function in Chinese people with long-term computer display light exposure. Br. J. Nutr. 2009, 102, 186-190.

[7] Borel, P., Grolier, P., Mekki, N., Boirie, Y., et al., Low and high responders to pharmacological doses of beta-carotene: proportion in the population, mechanisms involved and consequences on beta-carotene metabolism. J. Lipid Res. 1998, 39, 22502260.

[8] Gilbert, A. M., Stich, H. F., Rosin, M. P., Davison, A. J., Variations in the uptake of betacarotene in the oral mucosa of individuals after 3 days of supplementation. Int. J. Cancer $1990,45,855-859$.

[9] Lin, Y. M., Dueker, S. R., Burri, B. J., Neidlinger, T. R., Clifford, A. J., Variability of the conversion of beta-carotene to vitamin A in women measured by using a double-tracer study design. Am. J. Clin. Nutr. 2000, 71, 1545-1554. 
[10] Aleman, T. S., Cideciyan, A. V., Windsor, E. A., Schwartz, S. B., et al., Macular pigment and lutein supplementation in ABCA4-associated retinal degenerations. Invest. Ophthalmol. Vis. Sci. 2007, 48, 1319-1329.

[11] Hammond, B. R., Johnson, E. J., Russell, R. M., Krinsky, N. I., et al., Dietary modification of human macular pigment density. Invest Ophth Vis Sci 1997, 38, 17951801.

[12] Richer, S., Devenport, J., Lang, J. C., LAST II: Differential temporal responses of macular pigment optical density in patients with atrophic age-related macular degeneration to dietary supplementation with xanthophylls. Optometry 2007, 78, 213 219.

[13] Johnson, E. J., Russell, R. M., Distribution of orally administered beta-carotene among lipoproteins in healthy men. Am J Clin Nut 1992, 56, 128-135.

[14] Stahl, W., Schwarz, W., Vonlaar, J., Sies, H., All-trans beta-carotene preferentially accumulates in human chylomicrons and very low density lipoproteins compared with the 9-cis geometrical isomer. J. Nutr. 1995, 125, 2128-2133.

[15] Aleman, T. S., Duncan, J. L., Bieber, M. L., de Castro, E., et al., Macular pigment and lutein supplementation in retinitis pigmentosa and Usher syndrome. Invest. Ophthalmol. Vis. Sci. 2001, 42, 1873-1881.

[16] Borel, P., Factors affecting intestinal absorption of highly lipophilic food microconstituents (fat-soluble vitamins, carotenoids and phytosterols). Clin. Chem. Lab. Med. 2003, 41, 979-994.

[17] Pasquier, B., Armand, M., Castelain, C., Guillon, F., et al., Emulsification and lipolysis of triacylglycerols are altered by viscous soluble dietary fibres in acidic gastric medium in vitro. Biochem. J. 1996, 314, 269-275. 
[18] Borel, P., Armand, M., Pasquier, B., Senft, M., et al., Digestion and absorption of tubefeeding emulsions with different droplet sizes and compositions in the rat. JPEN $J$. Parenter. Enteral Nutr. 1994, 18, 534-543.

[19] Lakshman, M. R., Asher, K. A., Attlesey, M. G., Satchithanandam, S., et al., Absorption, storage, and distribution of beta-carotene in normal and beta-carotene-fed rats: roles of parenchymal and stellate cells. J. Lipid Res. 1989, 30, 1545-1550.

[20] Parker, R. S., Carotenoid and Tocopherol Composition of Human Adipose Tissue. Am. J. Clin. Nutr. 1988, 47, 33-36.

[21] Johnson, E. J., Suter, P. M., Sahyoun, N., Ribayamercado, J. D., Russell, R. M., Relation between beta-carotene intake and plasma and adipose tissue concentrations of carotenoids and retinoids. Am. J. Clin. Nutr. 1995, 62, 598-603.

[22] Carriere, F., Barrowman, J. A., Verger, R., Laugier, R., Secretion and contribution to lipolysis of gastric and pancreatic lipases during a test meal in humans. Gastroenterology 1993, 105, 876-888.

[23] Reboul, E., Berton, A., Moussa, M., Kreuzer, C., et al., Pancreatic lipase and pancreatic lipase-related protein 2 , but not pancreatic lipase-related protein 1 , hydrolyze retinyl palmitate in physiological conditions. Biochim. Biophys. Acta 2006, 1761, 4-10.

[24] Lombardo, D., Guy, O., Studies on the substrate specificity of a carboxyl ester hydrolase from human pancreatic juice. II. Action on cholesterol esters and lipid- soluble vitamin esters. Biochim. Biophys. Acta 1980, 611, 147-155.

[25] Zahalka, H. A., Shee, Cheng, C., Burton, G. W., Ingold, K. U., Hydrolysis of stereoisomeric alpha-tocopheryl acetates catalyzed by bovine cholesterol esterase. Biochim. Biophys. Acta 1987, 921, 481-485. 
[26] Lauridsen, C., Hedemann, M. S., Jensen, S. K., Hydrolysis of tocopheryl and retinyl esters by porcine carboxyl ester hydrolase is affected by their carboxylate moiety and bile acids. J Nutr Biochem 2001, 12, 219-224.

[27] Breithaupt, D. E., Bamedi, A., Wirt, U., Carotenol fatty acid esters: easy substrates for digestive enzymes? Comp. Biochem. Physiol. B Biochem. Mol. Biol. 2002, 132, 721-728.

[28] Chitchumroonchokchai, C., Failla, M. L., Hydrolysis of zeaxanthin esters by carboxyl ester lipase during digestion facilitates micellarization and uptake of the xanthophyll by Caco-2 human intestinal cells. J. Nutr. 2006, 136, 588-594.

[29] van Bennekum, A. M., Li, L., Piantedosi, R., Shamir, R., et al., Carboxyl ester lipase overexpression in rat hepatoma cells and CEL deficiency in mice have no impact on hepatic uptake or metabolism of chylomicron-retinyl ester. Biochemistry (Mosc.) 1999, $38,4150-4156$.

[30] Weng, W., Li, L., van Bennekum, A. M., Potter, S. H., et al., Intestinal absorption of dietary cholesteryl ester is decreased but retinyl ester absorption is normal in carboxyl ester lipase knockout mice. Biochemistry (Mosc.) 1999, 38, 4143-4149.

[31] Hollander, D., Ruble, P. E., beta-carotene intestinal absorption: bile, fatty acid, pH, and flow rate effects on transport. Am. J. Physiol. 1978, 235, E686-691.

[32] Terpstra, V., van Amersfoort, E. S., van Velzen, A. G., Kuiper, J., van Berkel, T. J., Hepatic and extrahepatic scavenger receptors: function in relation to disease. Arterioscler. Thromb. Vasc. Biol. 2000, 20, 1860-1872.

[33] Lobo, M. V., Huerta, L., Ruiz-Velasco, N., Teixeiro, E., et al., Localization of the lipid receptors CD36 and CLA-1/SR-BI in the human gastrointestinal tract: towards the identification of receptors mediating the intestinal absorption of dietary lipids. $J$. Histochem. Cytochem. 2001, 49, 1253-1260. 
[34] Krieger, M., Charting the fate of the "good cholesterol": identification and characterization of the high-density lipoprotein receptor SR-BI. Annu. Rev. Biochem. 1999, 68, 523-558.

[35] Hauser, H., Dyer, J. H., Nandy, A., Vega, M. A., et al., Identification of a receptor mediating absorption of dietary cholesterol in the intestine. Biochemistry (Mosc.) 1998, $37,17843-17850$.

[36] Bietrix, F., Yan, D., Nauze, M., Rolland, C., et al., Accelerated lipid absorption in mice overexpressing intestinal SR-BI. J. Biol. Chem. 2006, 281, 7214-7219.

[37] Reboul, E., Abou, L., Mikail, C., Ghiringhelli, O., et al., Lutein transport by Caco-2 TC7 cells occurs partly by a facilitated process involving the scavenger receptor class B type I (SR-BI). Biochem. J. 2005, 387, 455-461.

[38] van Bennekum, A., Werder, M., Thuahnai, S. T., Han, C. H., et al., Class B Scavenger Receptor-Mediated Intestinal Absorption of Dietary beta-Carotene and Cholesterol. Biochemistry (Mosc.) 2005, 44, 4517-4525.

[39] During, A., Doraiswamy, S., Harrison, E. H., Xanthophylls are preferentially taken up compared with beta-carotene by retinal cells via a SRBI-dependent mechanism. J. Lipid Res. 2008, 49, 1715-1724.

[40] Moussa, M., Landrier, J. F., Reboul, E., Ghiringhelli, O., et al., Lycopene absorption in human intestinal cells and in mice involves scavenger receptor class B type I but not Niemann-Pick C1-like 1. J. Nutr. 2008, 138, 1432-1436.

[41] Lobo, G. P., Hessel, S., Eichinger, A., Noy, N., et al., ISX is a retinoic acid-sensitive gatekeeper that controls intestinal beta,beta-carotene absorption and vitamin $\mathrm{A}$ production. FASEB J., 24, 1656-1666. 
[42] Cai, L., Eckhardt, E. R., Shi, W., Zhao, Z., et al., Scavenger receptor class B type I reduces cholesterol absorption in cultured enterocyte CaCo-2 cells. J. Lipid Res. 2004, $45,253-262$.

[43] Reboul, E., Klein, A., Bietrix, F., Gleize, B., et al., Scavenger receptor class B type I (SR-BI) is involved in vitamin E transport across the enterocyte. J. Biol. Chem. 2006, $281,4739-4745$.

[44] Reboul, E., Goncalves, A., Comera, C., Bott, R., et al., Vitamin D intestinal absorption is not a simple passive diffusion: Evidences for involvement of cholesterol transporters. Mol. Nutr. Food Res. 2011.

[45] Moussa, M., Gouranton, E., Gleize, B., Yazidi, C. E., et al., CD36 is involved in lycopene and lutein uptake by adipocytes and adipose tissue cultures. Mol. Nutr. Food Res. 2011, 55, 578-584.

[46] Davies, J. P., Levy, B., Ioannou, Y. A., Evidence for a Niemann-pick C (NPC) gene family: identification and characterization of NPC1L1. Genomics 2000, 65, 137-145.

[47] Altmann, S. W., Davis, H. R., Jr., Zhu, L. J., Yao, X., et al., Niemann-Pick C1 Like 1 protein is critical for intestinal cholesterol absorption. Science 2004, 303, 1201-1204.

[48] Davies, J. P., Scott, C., Oishi, K., Liapis, A., Ioannou, Y. A., Inactivation of NPC1L1 causes multiple lipid transport defects and protects against diet-induced hypercholesterolemia. J. Biol. Chem. 2005, 280, 12710-12720.

[49] Garcia-Calvo, M., Lisnock, J., Bull, H. G., Hawes, B. E., et al., The target of ezetimibe is Niemann-Pick C1-Like 1 (NPC1L1). Proc. Natl. Acad. Sci. U. S. A. 2005, 102, 81328137.

[50] Duval, C., Touche, V., Tailleux, A., Fruchart, J. C., et al., Niemann-Pick C1 like 1 gene expression is down-regulated by LXR activators in the intestine. Biochem. Biophys. Res. Commun. 2006, 340, 1259-1263. 
[51] Davis, H. R., Jr., Zhu, L. J., Hoos, L. M., Tetzloff, G., et al., Niemann-Pick C1 Like 1 (NPC1L1) is the intestinal phytosterol and cholesterol transporter and a key modulator of whole-body cholesterol homeostasis. J. Biol. Chem. 2004, 279, 33586-33592.

[52] Narushima, K., Takada, T., Yamanashi, Y., Suzuki, H., Niemann-pick C1-like 1 mediates alpha-tocopherol transport. Mol. Pharmacol. 2008, 74, 42-49.

[53] Abuasal, B., Sylvester, P. W., Kaddoumi, A., Intestinal absorption of gamma-tocotrienol is mediated by Niemann-Pick C1-like 1: in situ rat intestinal perfusion studies. Drug Metab. Dispos. 2010, 38, 939-945.

[54] During, A., Dawson, H. D., Harrison, E. H., Carotenoid Transport Is Decreased and Expression of the Lipid Transporters SR-BI, NPC1L1, and ABCA1 Is Downregulated in Caco-2 Cells Treated with Ezetimibe. J. Nutr. 2005, 135, 2305-2312.

[55] Dean, M., Hamon, Y., Chimini, G., The human ATP-binding cassette (ABC) transporter superfamily. J. Lipid Res. 2001, 42, 1007-1017.

[56] Moody, J. E., Millen, L., Binns, D., Hunt, J. F., Thomas, P. J., Cooperative, ATPdependent association of the nucleotide binding cassettes during the catalytic cycle of ATP-binding cassette transporters. J. Biol. Chem. 2002, 277, 21111-21114.

[57] Higgins, C. F., Linton, K. J., The ATP switch model for ABC transporters. Nat. Struct. Mol. Biol. 2004, 11, 918-926.

[58] Herron, K. L., McGrane, M. M., Waters, D., Lofgren, I. E., et al., The ABCG5 polymorphism contributes to individual responses to dietary cholesterol and carotenoids in eggs. J. Nutr. 2006, 136, 1161-1165.

[59] Bhosale, P., Larson, A. J., Frederick, J. M., Southwick, K., et al., Identification and characterization of a Pi isoform of glutathione S-transferase (GSTP1) as a zeaxanthinbinding protein in the macula of the human eye. J. Biol. Chem. 2004, 279, 49447-49454. 
[60] Bhosale, P., Li, B., Sharifzadeh, M., Gellermann, W., et al., Purification and partial characterization of a lutein-binding protein from human retina. Biochemistry (Mosc.) 2009, 48, 4798-4807.

[61] Hollander, D., Rim, E., Muralidhara, K. S., Vitamin K1 intestinal absorption in vivo: influence of luminal contents on transport. Am. J. Physiol. 1977, 232, E69-74.

[62] Velkov, T., Lim, M. L., Horne, J., Simpson, J. S., et al., Characterization of lipophilic drug binding to rat intestinal fatty acid binding protein. Mol. Cell. Biochem. 2009, 326, $87-95$.

[63] Chuang, S., Velkov, T., Horne, J., Porter, C. J., Scanlon, M. J., Characterization of the drug binding specificity of rat liver fatty acid binding protein. J. Med. Chem. 2008, 51, $3755-3764$

[64] Borel, P., Moussa, M., Reboul, E., Lyan, B., et al., Human fasting plasma concentrations of vitamin $\mathrm{E}$ and carotenoids, and their association with genetic variants in apo C-III, cholesteryl ester transfer protein, hepatic lipase, intestinal fatty acid binding protein and microsomal triacylglycerol transfer protein. Br. J. Nutr. 2009, 101, 680-687.

[65] von Lintig, J., Vogt, K., Vitamin A formation in animals: molecular identification and functional characterization of carotene cleaving enzymes. J. Nutr. 2004, 134, 251S-256S.

[66] Duszka, C., Grolier, P., Azim, E. M., Alexandre-Gouabau, M. C., et al., Rat intestinal beta-carotene dioxygenase activity is located primarily in the cytosol of mature jejunal enterocytes. J. Nutr. 1996, 126, 2550-2556.

[67] Grolier, P., Duszka, C., Borel, P., Alexandre-Gouabau, M. C., Azais-Braesco, V., In vitro and in vivo inhibition of beta-carotene dioxygenase activity by canthaxanthin in rat intestine. Arch. Biochem. Biophys. 1997, 348, 233-238.

[68] Lindqvist, A., Andersson, S., Cell type-specific expression of beta-carotene 15,15'-monooxygenase in human tissues. J. Histochem. Cytochem. 2004, 52, 491-499. 
[69] Amengual, J., Lobo, G. P., Golczak, M., Li, H. N., et al., A mitochondrial enzyme degrades carotenoids and protects against oxidative stress. FASEB J., 25, 948-959.

[70] Tyssandier, V., Choubert, G., Grolier, P., Borel, P., Carotenoids, mostly the xanthophylls, exchange between plasma lipoproteins. Int. J. Vitam. Nutr. Res. 2002, 72, 300-308.

[71] Borel, P., Moussa, M., Reboul, E., Lyan, B., et al., Human plasma levels of vitamin E and carotenoids are associated with genetic polymorphisms in genes involved in lipid metabolism. J. Nutr. 2007, 137, 2653-2659.

[72] Ortega, H., Castilla, P., Gomez-Coronado, D., Garces, C., et al., Influence of apolipoprotein E genotype on fat-soluble plasma antioxidants in Spanish children. Am. J. Clin. Nutr. 2005, 81, 624-632.

[73] Herbeth, B., Gueguen, S., Leroy, P., Siest, G., Visvikis-Siest, S., The lipoprotein lipase serine 447 stop polymorphism is associated with altered serum carotenoid concentrations in the Stanislas Family Study. J. Am. Coll. Nutr. 2007, 26, 655-662.

[74] Sharvill, D. E., Familial hypercarotinaemia and hypovitaminosis A. Proc. R. Soc. Med. 1970, 63, 605-606.

[75] McLaren, D. S., Zekian, B., Failure of enzymatic cleavage of b-carotene. The cause of vitamin A deficiency in a child. Am. J. Dis. Child. 1971, 121, 278-280.

[76] Monk, B. E., Metabolic carotenaemia. Br. J. Dermatol. 1982, 106, 485-487.

[77] Svensson, A., Vahlquist, A., Metabolic carotenemia and carotenoderma in a child. Acta Dermato - Venereologica 1995, 75, 70-71.

[78] Lindqvist, A., Sharvill, J., Sharvill, D. E., Andersson, S., Loss-of-function mutation in carotenoid 15,15'-monooxygenase identified in a patient with hypercarotenemia and hypovitaminosis A. J. Nutr. 2007, 137, 2346-2350. 
[79] Ferrucci, L., Perry, J. R., Matteini, A., Perola, M., et al., Common Variation in the betaCarotene 15,15'-Monooxygenase 1 Gene Affects Circulating Levels of Carotenoids: A Genome-Wide Association Study. Am. J. Hum. Genet. 2009.

[80] Borel, P., de Edelenyi, F. S., Vincent-Baudry, S., Malezet-Desmoulin, C., et al., Genetic variants in BCMO1 and CD36 are associated with plasma lutein concentrations and macular pigment optical density in humans. Ann. Med. 2010, 43, 47-59.

[81] Esquela-Kerscher, A., Slack, F. J., Oncomirs - microRNAs with a role in cancer. Nat. Rev. Cancer 2006, 6, 259-269.

[82] Ryan, B. M., Robles, A. I., Harris, C. C., Genetic variation in microRNA networks: the implications for cancer research. Nat. Rev. Cancer, 10, 389-402.

[83] Rautalahti, M., Albanes, D., Virtamo, J., Taylor, P. R., et al., Beta-carotene did not work: Aftermath of the ATBC study. Cancer Lett. 1997, 114, 235-236.

[84] Tian, R., Pitchford, W. S., Morris, C. A., Cullen, N. G., Bottema, C. D., Genetic variation in the beta, beta-carotene-9', 10'-dioxygenase gene and association with fat colour in bovine adipose tissue and milk. Anim. Genet. 2009.

[85] Vage, D. I., Boman, I. A., A nonsense mutation in the beta-carotene oxygenase 2 (BCO2) gene is tightly associated with accumulation of carotenoids in adipose tissue in sheep (Ovis aries). BMC Genet, 11, 10.

[86] Leung, W. C., Hessel, S., Meplan, C., Flint, J., et al., Two common single nucleotide polymorphisms in the gene encoding beta-carotene $15,15^{\prime}$-monoxygenase alter betacarotene metabolism in female volunteers. FASEB J. 2008. 


\section{Figure legends}

Figure 1. Interindividual variability in absorption efficiency of carotenoids. Example of lycopene.

Interindividual variability in absorption efficiency of lycopene as evaluated by measuring postprandial chylomicron lycopene concentrations after intake of a lycopene-rich test meal. The same test meal was ingested by 39 healthy male adults. It contained $50 \mathrm{~g}$ fat and $100 \mathrm{~g}$ tomato purée as a source of lycopene (unpublished data from a clinical study funded by the FP6 Integrated European project "Lycocard”, No. 016213). Bold curve: mean chylomicron lycopene concentrations of the 39 subjects. Dashed curves: curves of the lowest responder (lowest area under the curve (AUC)) and the highest responder (highest AUC). The ratio between the AUC of the highest responder and that of the lowest responder was about 20.

Figure 2. Proteins involved in carotenoid transport across the human enterocyte.

Carotenoids are captured from mixed micelles by apical membrane transporters (SR-BI, CD36 and NPC1L1). A fraction of carotenoids might then be effluxed back to the intestinal lumen via apical membrane transporters (SR-BI and possibly ABCG5/G8). Another fraction of carotenoids is transported to the site where they are incorporated in chylomicrons. A fraction of provitamin A carotenoids, e.g. $\beta$-carotene, $\alpha$-carotene, and $\beta$-cryptoxanthin, is transported to the site where they are cleaved into retinal by BCMO1. A fraction of nonprovitamin A carotenoids, e.g. lutein, zeaxanthin and lycopene, is possibly transported to mitochondria, where they are cleaved into apocarotenals by BCDO2. It is hypothesized that one or pore proteins are involved in intracellular transport of carotenoids, although they have not yet been identified. Good candidates are the FABPs. Non-metabolized carotenoids and retinyl esters, which originate from carotenoid cleavage by BCMO1 and subsequent metabolism by vitamin A enzymes, are secreted in the lymph in chylomicrons, while it is hypothesized that polar carotenoid metabolites are secreted in the portal route. 
Figure 3. Interindividual variability of absorption efficiency of carotenoids as explained by genetic variation in proteins involved in transport and metabolism of carotenoids in the enterocyte.

Ap: apical membrane transporter of carotenoids (e.g. SR-BI). Int: intracellular transporter of carotenoids (e.g. FABP). Cleav: enzyme involved in cleavage of carotenoids (e.g. BCMO1). A white symbol indicates that the protein works with maximal efficiency. A black symbol indicates that a genetic variation (e.g. an SNP) leads to an impaired expression or activity of the protein. A grey transporter indicates that a genetic variation leads to an intermediate expression or activity of the protein. The hypothesis is as follows: when most proteins involved in the metabolism of a carotenoid are efficient, subjects absorb the carotenoid very well: these subjects are called "high responders". When most of the proteins involved in the metabolism of a carotenoid are inefficient, subjects absorb the carotenoid very poorly: these are called "low responders". When some proteins are efficient and some are inefficient, the subjects absorb carotenoids with an intermediate efficiency; these are called "medium responders". This hypothesis explains the Gaussian response to $\beta$-carotene described in a clinical study [7]. 